\title{
Haemolytic anaemia in a case of occupational asthma due to maleic anhydride
}

\author{
P F G Gannon, P Sherwood Burge, C Hewlett, R D Tee
}

Occupational asthma due to a number of acid anhydrides including maleic anhydride has previously been described..$^{12}$ Haemolytic anaemia in association with pulmonary haemorrhage has been described in workers exposed to trimellitic anhydride, ${ }^{3}$ but not in workers exposed to maleic anhydride. The previously reported cases of haemolytic anaemia were Coombs' negative. We describe a case of autoimmune haemolytic anaemia in a worker with occupational asthma due to maleic anhydride and with no associated pulmonary haemorrhage.

A 57 year old non-atopic non-smoking male laboratory supervisor with no pre-existing asthma started work on a pilot plant producing maleic anhydride in the 1950s. Shortly after this he developed work related wheeze and breathlessness and was transferred to paperwork away from exposure, with resolution of his symptoms. In 1982 he began work in the company's analytical laboratory where he was intermittently exposed to maleic anhydride and had a recurrence of his work related wheeze and breathlessness; symptoms improved over periods away and deteriorated on return to work. Exposure continued, however, and in September 1984 he was admitted to hospital with a severe haemolytic anaemia (table). This responded to steroid, plasmapheresis, and blood transfusion. $\mathrm{He}$ returned to work away from exposure and his steroids were discontinued. His haemoglobin concentration remained stable (figure). $\mathrm{He}$ returned to exposure, however, at the end of May 1985 and within two weeks had been readmitted with a recurrence of his anaemia (figure); this again responded to treatment. He has not returned to exposure to

Occupational Lung Disease Unit, East Birmingham Hospital, Bordesley Green East, Birmingham B9 5ST

P F G Gannon, P Sherwood Burge

Department of Pathology, Royal Gwent Hospital, Newport, Gwent

C Hewlett

Department of Occupational Medicine, National

Heart and Lung Institute, Emmanuel Kaye Building,

Manresa Road, London SW3 6LR

R D Tee maleic anhydride and his haemoglobin concentration has remained stable in the normal range even though steroid treatment has been discontinued. At no time did he complain of symptoms suggestive of pulmonary haemorrhage. He now works as an antique restorer. He continues to have some asthma but this is well controlled and is not made worse by work.

Anhydride-human serum albumin (HSA) conjugates were prepared for maleic (MA), phthalic (PA) trimellitic (TMA), and tetrachlorphthalic anhydride (TCPA) and specific IgE antibodies were measured by radioallergosorbent test (RAST) as described by Topping et al. ${ }^{4}$ Positive RAST ratios of $24 \cdot 0$ for MA:HSA, 18.7 for PA:HSA, 17.0 for TMA:HSA, and 1.0 for TCPA:HSA were found. The RAST ratios were calculated as isotope binding of anhydride disc divided by isotope binding of HSA disc. A ratio of two or greater was taken as positive. We have subsequently monitored a decline in his IgE RASTs to these anhydrides consistent with removal from exposure. He did, however, have a small increase in his IgE RASTs at one point, which we believe to be the result of environmental exposure as he still lives near to his original workplace. His IgG antibodies to acid anhydrides have been negative throughout. Exposure to maleic anhydride is the likely cause of haemolytic anaemia and occupational asthma in the worker. This is suggested by the temporal relation between episodes of haemolytic anaemia and work related symptoms and exposure to maleic anhydride and the high specific IgE RAST score to this agent. The positive RAST scores to other anhydrides are likely to be a result of cross reactivity as only maleic anhydride was present in the workplace; this is supported by the negative RAST ratio of TCPA:HSA. The Coombs' positive nature of

Investigations on initial admission to hospital in 1984

Investigation

Haemoglobin concentration

Reticulocytes

White cell count

Platelets

Total bilirubin concentration

Lactate dehydrogenase activity

Coombs' test

Normal range in parentheses. 


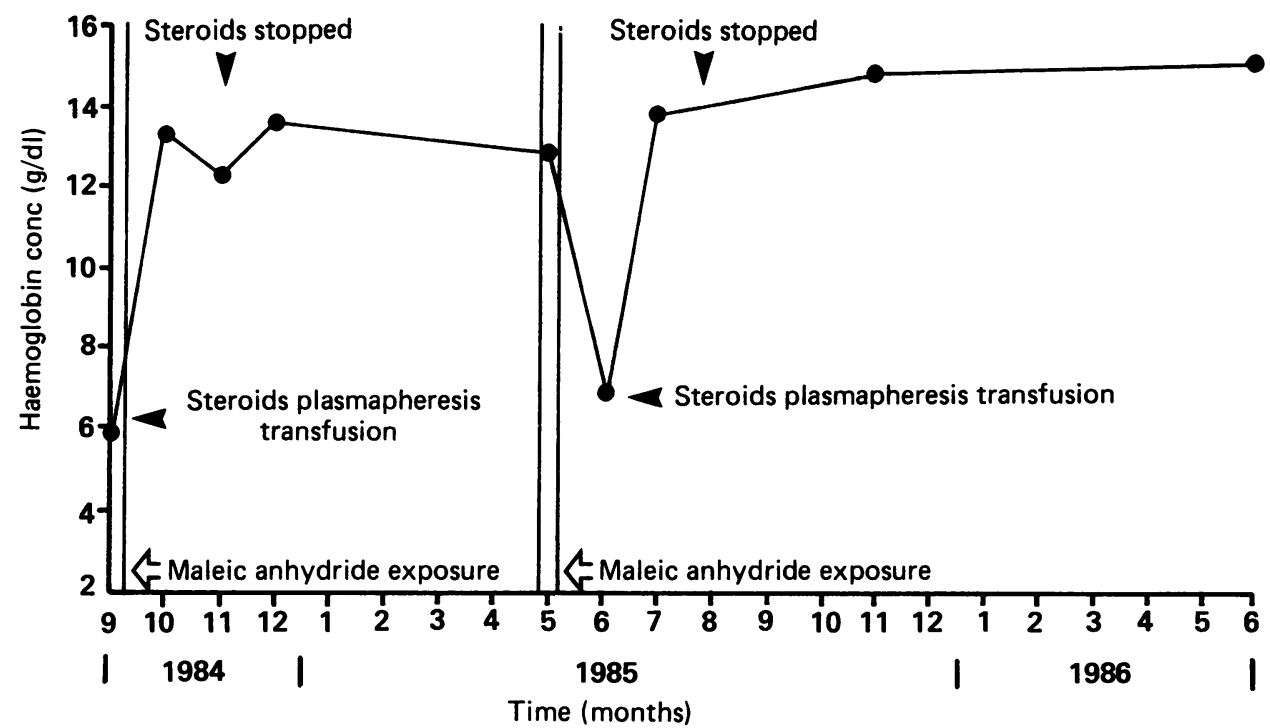

Plot of haemoglobin concentration against time showing time related falls compared with exposure to maleic anhydride.

the anaemia suggests that this is an immune mediated reaction although we were unable to find any antibodies to a maleic anhydride human red cell conjugate. An immune mechanism is likely in view of the fact that maleic anhydride has been used in the past to chemically modify erythrocyte membrane proteins $s^{5}$; effectively producing a foreign protein. This case contrasts with cases of haemolytic anaemia caused by trimellitic anhydride, which were considered to be non-immunologically mediated and were associated with pulmonary haemorrhage.

Requests for reprints to: Dr P F G Gannon, Occupational Lung Disease Unit, East Birmingham Hospital, Bordesley Green East, Birmingham B9 5ST.
1 Guerin JC, Deschamps O, Guillot TL, Chavallion JM, Kalb JC. A propos d'un cas d'asthme a l'anhydride maleique. Pouman et le Coer 1980;36:393-5.

2 Lee HS, Wang WT, Cheong TH, Tan KT, Chee BE, Narendran $\mathrm{K}$. Occupational asthma due to maleic anhydride. $\mathrm{Br} J$ Ind Med 1991;48:283-5.

3 Ahmad D, Morgan WKC, Patterson R, Williams T, Raymond Zeiss C. Pulmonary haemorrhage and haemolytic anaemia due to trimellitic anhydride. Lancet 1979;ii:328-30.

4 Topping MD, Venables KM, Luczynska CM, Howe $W$, Newman Taylor AJ. Specificity of the human IgE response to inhaled acid anhydrides. J Allergy Clin Immunol 1986;77: 834-42.

5 Ong CN, Lee WR. Interaction of calcium and lead in human erythrocytes. Br J Ind Med 1980;37:70-7.

Accepted 3 June 1991 